Swarthmore College

Works

7-1-1996

\title{
Oxidative Stress Detection With Escherichia Coli Harboring A
} katG'::lux Fusion

S. Belkin

D. R. Smulski

Amy Cheng Vollmer

Swarthmore College, avollme1@swarthmore.edu

T. K. Van Dyk

R. A. LaRossa

Follow this and additional works at: https://works.swarthmore.edu/fac-biology

Part of the Biology Commons, and the Microbiology Commons

Let us know how access to these works benefits you

\section{Recommended Citation}

S. Belkin, D. R. Smulski, Amy Cheng Vollmer, T. K. Van Dyk, and R. A. LaRossa. (1996). "Oxidative Stress Detection With Escherichia Coli Harboring A katG'::lux Fusion". Applied And Environmental Microbiology. Volume 62, Issue 7. 2252-2256.

https://works.swarthmore.edu/fac-biology/389

This work is brought to you for free by Swarthmore College Libraries' Works. It has been accepted for inclusion in Biology Faculty Works by an authorized administrator of Works. For more information, please contact myworks@swarthmore.edu. 


\title{
Oxidative Stress Detection with Escherichia coli Harboring a $k a t G^{\prime}:: l u x$ Fusion
}

\author{
SHIMSHON BELKIN,,${ }^{1,2 *}$ DANA R. SMULSKI ${ }^{2}$ AMY C. VOLLMER,${ }^{1 \dagger}$ \\ TINA K. VAN DYK, ${ }^{2}$ AND ROBERT A. LAROSSA ${ }^{2}$ \\ Environmental Microbiology, Desert Research Institute, Ben-Gurion University of the Negev, \\ Sede-Boqer 84993, Israel, ${ }^{1}$ and DuPont Company Central Research and Development, \\ Experimental Station, Wilmington, Delaware 19880-0173²
}

Received 27 November 1995/Accepted 15 April 1996

\begin{abstract}
A plasmid containing a transcriptional fusion of the Escherichia coli katG promoter to a truncated Vibrio fischeri lux operon (luxCDABE) was constructed. An $E$. coli strain bearing this plasmid (strain DPD2511) exhibited low basal levels of luminescence, which increased up to 1,000 -fold in the presence of hydrogen peroxide, organic peroxides, redox-cycling agents (methyl viologen and menadione), a hydrogen peroxideproducing enzyme system (xanthine and xanthine oxidase), and cigarette smoke. An oxyR deletion abolished hydrogen peroxide-dependent induction, confirming that oxy $R$ controlled $k a t G^{\prime}:$ :lux luminescence. Light emission was also induced by ethanol by an unexplained mechanism. A marked synergistic response was observed when cells were exposed to both ethanol and hydrogen peroxide; the level of luminescence measured in the presence of both inducers was much higher than the sum of the level of luminescence observed with ethanol and the level of luminescence observed with hydrogen peroxide. It is suggested that this construction or similar constructions may be used as a tool for assaying oxidant and antioxidant properties of chemicals, as a biosensor for environmental monitoring, and as a tool for studying cellular responses to oxidative hazards.
\end{abstract}

Active oxygen species are highly damaging to all living organisms, and aerobically grown cells cannot survive without adequate protection against the toxic effects of these molecules (9). The importance of oxidative stress and damage in biology, agriculture, and medicine is gaining more recognition, as is the significance of antioxidant activity for cellular well-being $(5,7$, 9).

Of the various active oxygen species, the free radicals are usually considered the most hazardous. Hydrogen peroxide, although chemically less reactive, is nevertheless a threat to the structure and function of proteins, nucleic acids, lipids, and membranes, whether it is added externally or produced intracellularly (9). The damage inflicted by hydrogen peroxide, as well as many organic peroxides, is due either to intrinsic oxidative activity or to production of hydroxyl radicals.

Several enzymatic systems have evolved to eliminate peroxides and combat their deleterious effects. In both Escherichia coli and Salmonella typhimurium, the oxyR regulon is the beststudied of these defense circuits. Exposure to $\mathrm{H}_{2} \mathrm{O}_{2}$ leads to induction of at least 30 proteins, 9 of which are under direct positive control of the OxyR protein $(7,17,18)$. These include a catalase (HPI) that is encoded by the kat $G$ gene.

In the framework of a project aimed at the generation of a panel of bacterial biosensors for environmental stress, several E. coli strains which respond to oxidative stress by the production of light were designed and constructed $(2,3,20)$. One group of these strains, which are responsive to the presence of superoxide radicals, will be described elsewhere (3a). In this paper we describe the construction and characterization of a peroxide-responsive biosensor. To construct this biosensor, the

\footnotetext{
* Corresponding author. Mailing address: Environmental Microbiology, Ben-Gurion University of the Negev, The J. Blaustein Desert Research Institute, Sede-Boqer 84993, Israel. Phone: 972-7-565767. Fax: 972-7-565835. Electronic mail address: belkin@bgumail.bgu.ac.il. $\dagger$ Present address: Swarthmore College, Swarthmore, PA 190811397.
}

oxy $R$-activated promoter of the katG (catalase) gene, under positive control of $o x y R$, was fused to Vibrio fischeri lux $C D A B E$ genes so that kat $G$ induction led to light emission.

\section{MATERIALS AND METHODS}

Plasmids and $\boldsymbol{E}$. coli strains. Plasmid pKatGLux2 containing a transcriptional fusion of the $\mathrm{kat} G$ promoter region to the luxCDABE genes was constructed by a method similar to the method described previously (21). The kat $G$ promoter was obtained by PCR amplification (GeneAmp PCR reagent kit; Perkin-Elmer Cetus, Norwalk, Conn.) of a 654-bp segment, using lambda phage 538 of the Kohara collection $(4,10)$ as the template. The primers used were 5'-ACTTA AGGATCCCGAAATGAGGGCGGGAAA-3' and 5'-AGCAGCGAATTC GAACGTTGCTGACCACGA-3'; these primers included nucleotides -235 to -218 and +406 to +390 relative to the start of $k a t G$ transcription (19), as well as additional nucleotides containing Bam HI and EcoRI restriction sites, respectively. Following digestion with BamHI and EcoRI, the PCR products were directionally ligated to BamHI- and EcoRI-digested pUCD615, a plasmid containing the promoterless luxCDABE operon of $V$. fischeri (14), which created the desired operon fusion. Plasmid pKatGLux2 was moved into E. coli RFM443 (12) by $\mathrm{CaCl}_{2}$-mediated transformation (15) to yield strain DPD2511. For further studies plasmid pKatGLux2 was also placed in a pair of isogenic hosts, one of which was an $\operatorname{oxy} R$ mutant (1), by $\mathrm{CaCl}_{2}$ transformation (15). The host strains and the resulting transformants are listed in Table 1 . Table 1 also lists strains containing other lux fusion plasmids, detailed descriptions of which have been or will be published elsewhere.

Insertion verification. The sequence, size, and orientation of the kat $G$ promoter in pKatGLux2 were verified by using the two approaches described below.

The size and orientation of the inserted DNA were verified by PCR amplification, using the isolated plasmid DNA as the template and a pair of primers one of the primers was from the luxI region of pUCD615 (23), and the other was the $5^{\prime}$ primer used for amplification of the original promoter fragment from $E$. coli DNA. The size of the amplified fragment was very similar to the calculated size $(1,454 \mathrm{bp})$

The sequence of $480 \mathrm{bp}$ in the $k a t G$ promoter region in plasmid DNA isolated from DPD2511 was determined in one direction by using the Promega Silver Sequence kit. The following modifications were made to the procedure outlined in the manufacturer's November 1993 manual: the long glass plate was treated each time with Sigmacote; the $6 \%$ Long Ranger gels contained 1.2 $\times$ TBE and were electrophoresed with $0.6 \times$ TBE electrophoresis buffer; amplification profile 1 was used; DNA samples were heated to $75^{\circ} \mathrm{C}$ for 5 to 8 min just prior to loading; and the developing solution was maintained at 4 to $6^{\circ} \mathrm{C}$ until just prior to use, split into 1-liter aliquots, and used in succession. The illumination times required for transfer of the silver-stained banding image from the air-dried gel to EDF film were 5 to $20 \mathrm{~s}$. Development of the EDF film with an automated film processor was made possible by attaching a 2- to 3-in. (ca. 5.08- to 7.62-cm) strip 
TABLE 1. E. coli plasmids and strains used in this study

\begin{tabular}{|c|c|c|}
\hline Plasmid or strain & Description & Reference \\
\hline \multicolumn{3}{|l|}{ Plasmids } \\
\hline pUCD615 & $A m p^{\mathrm{r}} \mathrm{Kan}^{\mathrm{r}}$, multiple cloning site upstream of luxCDABE & 14 \\
\hline pKatGLux2 & Same as pUCD615, but $k a t G^{\prime}:: \operatorname{lux} C D A B E$ & This study \\
\hline pMicFLux1 & Same as pUCD615, but mic $F^{\prime}:: \operatorname{lux} C D A B E$ & Unpublished data \\
\hline pGrpELux5 & Same as pUCD615, but $\operatorname{grp}^{\prime}::$ luxCDABE & 21 \\
\hline pRecALux3 & Same as pUCD615, but rec $A^{\prime}:: \operatorname{lu} x C D A B E$ & Unpublished data \\
\hline \multicolumn{3}{|l|}{ Parental strains } \\
\hline RFM443 & galK2 lac74 rpsL200 & 12 \\
\hline K-12 & & 1 \\
\hline GS08 & Same as K-12, but $\operatorname{oxy} R::$ Kan & 1 \\
\hline \multicolumn{3}{|c|}{ Strains used in this study } \\
\hline DPD2511 & pKatGLux2/RFM443 & This study \\
\hline TV1061 & pGrpELux5/RFM443 & 21 \\
\hline DPD2794 & pRecALux3/RFM443 & 2,3 \\
\hline DPD 1554 & pKatGLux2/GS08 & This study \\
\hline DPD1560 & pKatGLux2/K12 & This study \\
\hline DPD1553 & pMicFLux1/GS08 & This study \\
\hline
\end{tabular}

of previously exposed and processed type XAR film to the EDF film with labeling tape.

One mismatch with the previously published $k a t G$ (19) sequence, which was not near or in any known control region, was found.

Cell culture and experimental procedure. All E. coli strains were grown in Luria-Bertani (LB) medium (13) at $26^{\circ} \mathrm{C}$. To assay for luminescence, cells grown overnight in the presence of kanamycin sulfate $(25 \mathrm{mg} /$ liter $)$ were diluted to a concentration of approximately $10^{7}$ cells per $\mathrm{ml}$ in fresh LB medium without kanamycin and were allowed to grow at $26^{\circ} \mathrm{C}$ for 2 to $3 \mathrm{~h}$. A $50-\mu \mathrm{l}$ portion of the culture was added to each well of an opaque white microtiter plate (Dynatech) that contained a series of twofold dilutions of the compounds to be tested in 50 $\mu \mathrm{l}$ of LB medium. Luminescence was monitored with a temperature-controlled $\left(26^{\circ} \mathrm{C}\right)$ microtiter plate luminometer (model ML3000; Dynatech) as described previously (21).

Luminescence values were expressed in the instrument's arbitrary relative light units (RLU). The maximal response ratios were the highest ratios of luminescence in the sample-containing wells to luminescence in wells containing untreated cells determined during a specified period.

Cigarette smoke effect. To study the effect of cigarette smoke on kat $\mathrm{G}$ expression, exponentially growing cells in LB medium at $26^{\circ} \mathrm{C}$ were split into two $10-\mathrm{ml}$ samples, each in a screw-cap 50-ml Erlenmeyer flask. Into one of the flasks a single puff of smoke from a commercially available cigarette was exhaled, and both flasks were then incubated at $26^{\circ} \mathrm{C}$ with shaking for an additional $10 \mathrm{~min}$. Samples $(50 \mu \mathrm{l})$ were then added to the wells of a microtiter plate that contained $50 \mu \mathrm{l}$ of fresh LB medium, and the plate was immediately placed in the luminometer.

Enzymes and chemicals. All of the chemicals used were analytical grade. Hydrogen peroxide and isopropanol were obtained from J. T. Baker Chemical Co., ethanol was obtained from Quantum Chemical Corp., organic peroxides were obtained from Aldrich, and the remaining compounds (menadione, methyl viologen, and xanthine) and enzymes (catalase, superoxide dismutase, and xanthine oxidase) were obtained from Sigma Chemical Co.

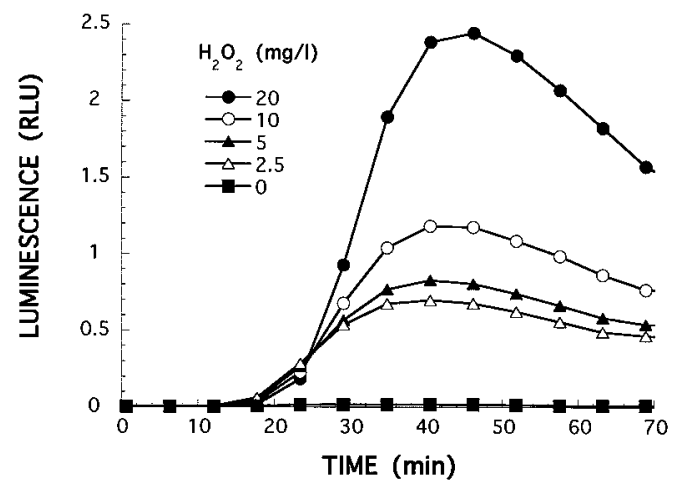

FIG. 1. Effects of $\mathrm{H}_{2} \mathrm{O}_{2}$ on bioluminescence of $E$. coli DPD2511.

\section{RESULTS}

Responses to peroxides. The response of strain DPD2511, the $k a t G^{\prime}:: l u x$-containing construction, to different hydrogen peroxide concentrations is shown in Fig. 1. A lag phase approximately $20 \mathrm{~min}$ long was followed by an increase in luminescence, which peaked after approximately $45 \mathrm{~min}$ and then declined. The response was dose dependent, with concentrations of more than $50 \mathrm{mg} /$ liter resulting in inhibition of luminescence (data not shown). Other experiments (data not shown) revealed that significant induction of the $k a t G$ fusion can be observed at hydrogen peroxide concentrations as low as $0.1 \mathrm{mg} / \mathrm{liter}$.

Strain DPD2511 also exhibited a clear response to organic peroxides (Fig. 2), with luminescence kinetics very similar to those observed with hydrogen peroxide. Four different organic peroxides were tested at a broad range of concentrations. Two of these compounds, cumene hydroperoxide and tert-butyl hydroperoxide, elicited responses similar in magnitude to the response induced by $\mathrm{H}_{2} \mathrm{O}_{2}$. tert-Butyl perbenzoate elicited a clear but small response at the higher end of the concentration range tested ( $1 \mathrm{~g} /$ liter), and DL-tertbutylperoxide resulted in no induction at any of the concentrations tested (data not shown).

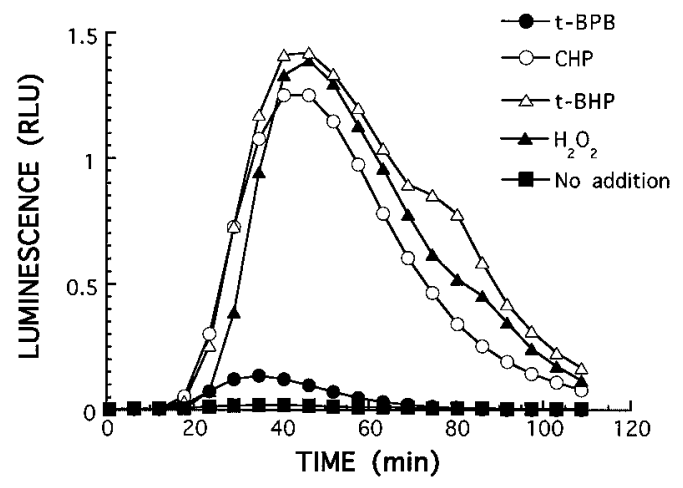

FIG. 2. Response of strain DPD2511 to organic peroxides. The concentrations used are the concentrations which elicited the maximal response for each compound, as follows: tert-butyl perbenzoate (t-BPB), $1 \mathrm{~g} /$ liter; cumene hydroperoxide (CHP), $125 \mathrm{mg} /$ liter; tert-butyl hydroperoxide (t-BHP), $22 \mathrm{mg} /$ liter. The $\mathrm{H}_{2} \mathrm{O}_{2}$ concentration used was $38 \mathrm{mg} /$ liter. 




FIG. 3. Xanthine and xanthine oxidase effects on DPD2511 luminescence. The following concentrations were used: xanthine $(\mathrm{X}), 1 \mathrm{mM}$; xanthine oxidase (XO), $0.125 \mathrm{U} / \mathrm{ml}$; catalase, $640 \mathrm{U} / \mathrm{ml}$; and superoxide dismutase (SOD), 138 $\mathrm{U} / \mathrm{ml}$.

Figure 3 shows the response of strain DPD2511 to peroxides generated enzymatically by the action of xanthine oxidase on xanthine. Very strong induction in the presence of both enzyme and substrate was observed, while xanthine alone elicited no response. Interestingly, induction of luminescence occurred repeatedly in response to xanthine oxidase when there was no externally introduced substrate. Luminescence in response to the presence of both xanthine and xanthine oxidase was partially sensitive to the addition of superoxide dismutase and was completely abolished by catalase (Fig. 3). Of the two active oxygen species potentially generated by xanthine oxidase activity, superoxide and $\mathrm{H}_{2} \mathrm{O}_{2}(6)$, the latter appeared to be the ultimate inducer of the katG promoter. While the actual peroxide concentrations to which the cells were exposed were not calculated, it is possible that the relatively gradual generation of the oxidants allowed induction stronger than the induction observed with $\mathrm{H}_{2} \mathrm{O}_{2}$ or organic peroxide treatments (Fig. 1 and 2).

Responses to other treatments. While peroxides elicited the strongest response from DPD2511, other compounds also induced luminescence in this strain. These compounds included redox cycling agents, such as methyl viologen or menadione, which produce superoxide radicals. The response to these compounds was similar in magnitude to the response elicited by $\mathrm{H}_{2} \mathrm{O}_{2}$, a phenomenon which may be explained by the intracellular conversion of superoxide radicals to hydrogen peroxide by superoxide dismutase. Indeed, menadione-induced lumines- cence was dramatically diminished in the presence of catalase (Fig. 4).

Alcohols, such as isopropanol and ethanol, were another class of compounds which induced significant luminescence in strain DPD2511. Furthermore, the presence of both ethanol and $\mathrm{H}_{2} \mathrm{O}_{2}$ appeared to have a marked synergistic effect on this induction (Fig. 5); the luminescence observed in the presence of both inducers was far greater than the luminescence expected from the sum of the responses to the individual compounds. It is yet to be determined if the synergy occurred at the level of gene activation or whether the effect was on luciferase activity.

Specificity of the peroxide response. Strain DPD2511 is one of a series of $E$. coli constructions (2, 3, 20-23) containing plasmids on which lux genes are fused to various stress promoters. Several of these constructions also responded to oxidative stress exerted by various agents, including peroxides. In order to highlight the enhanced specificity of the $k a t G^{\prime}:: l u x$ fusion for $\mathrm{H}_{2} \mathrm{O}_{2}$, its reactivity and the reactivities of two other strains which exhibited significant responses were compared (Fig. 6). Strain TV1061 carries a plasmid with a $g r p E^{\prime}:: l u x$ fusion and has been shown to be a sensitive reporter of heat shock induction (21). DPD2794 contains a rec $A^{\prime}:: l u x$ fusion and as such is a potential biosensor for SOS-inducing agents (2, $3,24)$. Figure 6 clearly shows that DPD2511 was indeed induced to much higher levels than the other strains; at 50 $\mathrm{mg} /$ liter, a concentration which led to maximal induction in all three strains, the luminescence of DPD2511 increased 800fold, compared with 70-fold for TV1061 and approximately 20 -fold for DPD2794. Figure 6 also shows that the $k a t G^{\prime}:: l u x$ fusion was much more sensitive than the other fusions; at 1.6 $\mathrm{mg} /$ liter, DPD2511 exhibited 20-fold induction, compared with the 2.5-fold induction exhibited by DPD2794 and the lack of induction exhibited by TV1061.

To demonstrate that the induced luminescence observed in strain DPD2511 was indeed under the control of the oxyR regulatory circuit, the plasmid bearing the $k a t G^{\prime}:: l u x$ fusion was inserted into an isogenic pair of $E$. coli hosts, one of which was defective in the oxyR circuit (Table 1). Figure 7A shows that the $\operatorname{oxy} R$ mutation eliminated peroxide induction. To show that this effect was specific to the $k a t G^{\prime}:: l u x$-bearing plasmid, induction of luminescence by an $o x y R$-independent reporter was examined in the same $\operatorname{oxy} R$ host. As shown in Fig. 7B, induction of the mic $F^{\prime}:: l u x$ fusion, which was responsive to oxygen radicals (under soxRS control [7, 8]), by the redoxcycling agent methyl viologen was not affected by the $\operatorname{oxy} R$ null mutation.

Response to cigarette smoke. Several potential uses can be

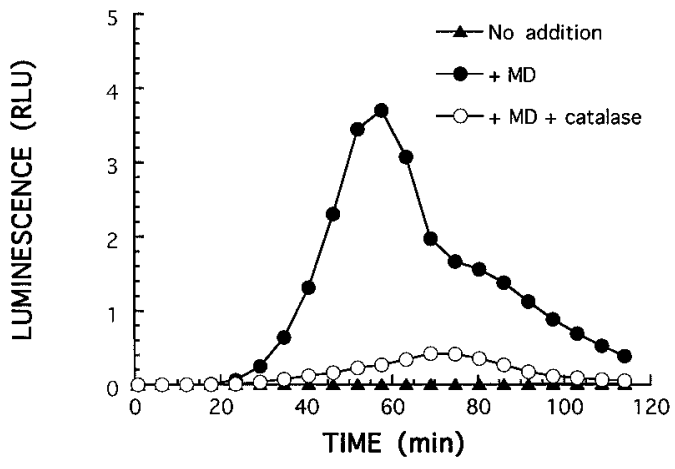

FIG. 4. Effect of catalase $(640 \mathrm{U} / \mathrm{ml})$ on DPD2511 luminescence induced by menadione $(\mathrm{MD})(4 \mathrm{mg} / \mathrm{ml})$



FIG. 5. Synergistic effect of $\mathrm{H}_{2} \mathrm{O}_{2}(6 \mathrm{mg} /$ liter) and ethanol (2\%) on DPD2511 luminescence. 


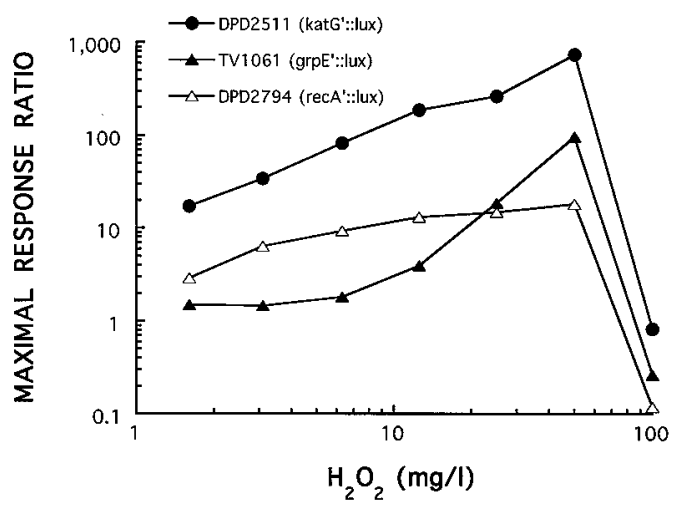

FIG. 6. Responses to $\mathrm{H}_{2} \mathrm{O}_{2}$ of three E. coli constructions, each carrying a different promoter::lux fusion. Each point represents the maximal response ratio observed during $120 \mathrm{~min}$ of exposure of the cells to the given peroxide concentration. The maxima were reached after 40 to $60 \mathrm{~min}$ in strains DPD2511 and TV1061 and after 100 to $120 \mathrm{~min}$ in strain DPD2794.

envisioned for bacterial strains bearing $k a t G^{\prime}:: l u x$ and similar fusions; these organisms could be used as reporters of intracellular oxidative stress, as a convenient assay system for antioxidant activities, or as biosensors for potential environmental oxidative hazards. Strain DPD2511 has been shown to be responsive to different types of environmentally significant pollutants and chemical industrial wastewater $(2,3,3 \mathrm{a})$. A somewhat different use is shown in Fig. 8, which shows the induction of luminescence by exposure to a puff of cigarette smoke for 10 min. While this experiment could not provide quantitative data concerning the oxidative effects of cigarette smoke or any of its numerous constituents, it very clearly demonstrated that oxidative hazards were present and suggested a rapid way for detecting them.

\section{DISCUSSION}

In this paper we describe an E. coli strain that carries a plasmid in which the $V$. fischeri lux structural genes are fused to the promoter for a catalase-specifying gene (katG). Luminescence was induced in this strain by the presence of $\mathrm{H}_{2} \mathrm{O}_{2}$, which was added externally (Fig. 1, 2, 5, and 6), produced extracellularly by xanthine oxidase (Fig. 3), or perhaps generated internally by superoxide dismutase (Fig. 4). The strain which we used was also highly responsive to organic peroxides
(Fig. 2), to redox-cycling agents (Fig. 4), and to cigarette smoke (Fig. 8). The response of the strain was shown to be under the control of the oxyR regulon (3) (Fig. 7), the main $E$. coli circuit for defense against peroxide stress. Luminescence in strain DPD2511 was also induced by short-chain alcohols, such as ethanol (Fig. 5). The nature of this effect is being investigated; preliminary results indicate that the effect of ethanol, a known heat shock inducer, may also be at least partially oxidative and dependent on oxyR function (3a).

In most previously described studies of the use of bacterial luminescence as a genetic reporter, the workers used only two genes, $\operatorname{lu} x A$ and $\operatorname{lu} x B$, which encode the two subunits of luciferase $(11,16)$. In these studies, addition of a long-chain aldehyde as a substrate for the luciferase was necessary. The plasmid used in our study contains a single transcriptional unit which also includes luxCDE, which simplifies the experimental procedure by eliminating the need for external aldehyde addition. A danger inherent in such a construction is an increase in the probability that light emission will be affected by parameters that are not related to the promoter-driven expression of lux. Such parameters, however, tend to inhibit luminescence rather than enhance it. The fact that the responses of strain DPD2511 are consistently dose dependent suggests that if such inhibitory effects are present, they are relatively insignificant.

To satisfy future experimental and diagnostic needs, increased sensitivity to oxidative agents may be required. One possible approach may be to modify or replace the host bacterium (21), which would allow increased permeability or intracellular accumulation. Another possible avenue is suggested by the synergistic effect demonstrated in Fig. 5. The presence of a small amount of an "enhancer" compound (in this case ethanol) may dramatically increase the inductive effects of compounds whose influence is otherwise hardly noticeable. The nature of the synergy in this case is not clear. There are indications that ethanol-dependent synergy of heat shock induction may occur on a transcriptional level (22), but it remains to be determined whether this is true for $\operatorname{oxy} R$-dependent induction.

In summary, strain DPD2511 appears to be a sensitive tool for detecting stress exerted by different types of oxidative agents, as well as for quantifying the effects of the agents. The following three major uses can be envisioned for this construction or similar constructions. (i) They may be used to study the regulation of cellular responses to oxidative hazards; in contrast to most other genetic reporter systems, lux expression can be monitored in vivo, which allows real-time monitoring of the

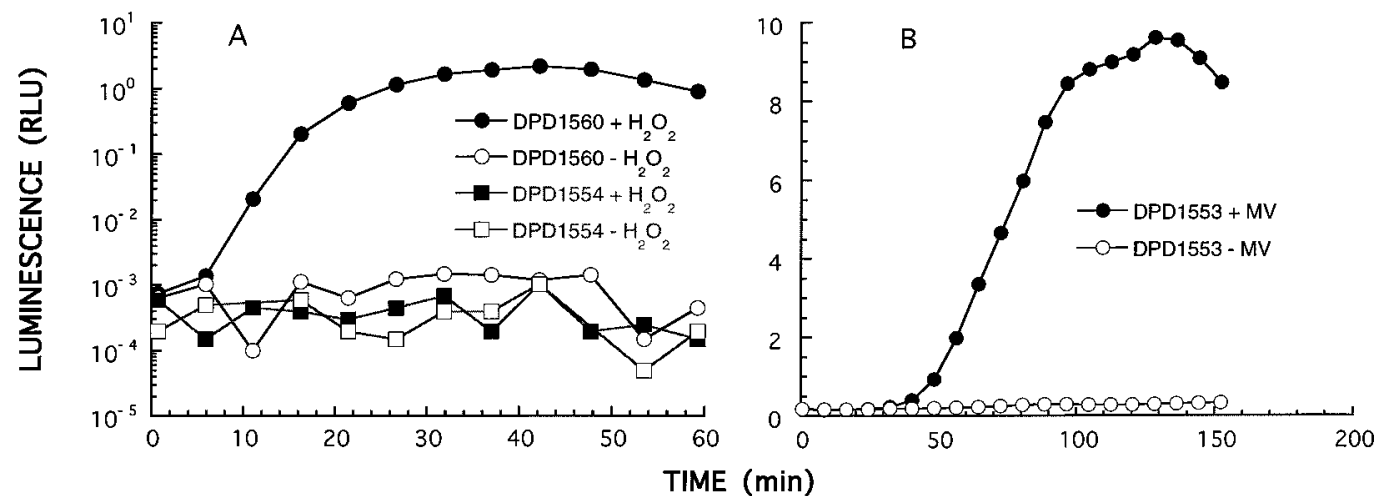

FIG. 7. $\mathrm{H}_{2} \mathrm{O}_{2}$-induced luminescence in the $k a t G^{\prime}:$ :lux fusion is controlled by oxyR. (A) Strains DPD1554 (oxyR::kan) and DPD1560 (oxy $R^{+}$), both containing pKatGLux2, challenged with $\mathrm{H}_{2} \mathrm{O}_{2}(3 \mathrm{mg} /$ liter). (B) Strain DPD1553, containing pMicFLux1 in the oxyR mutant, challenged with methyl viologen (MV) (1 mg/ml). See Table 1 for strain descriptions. 


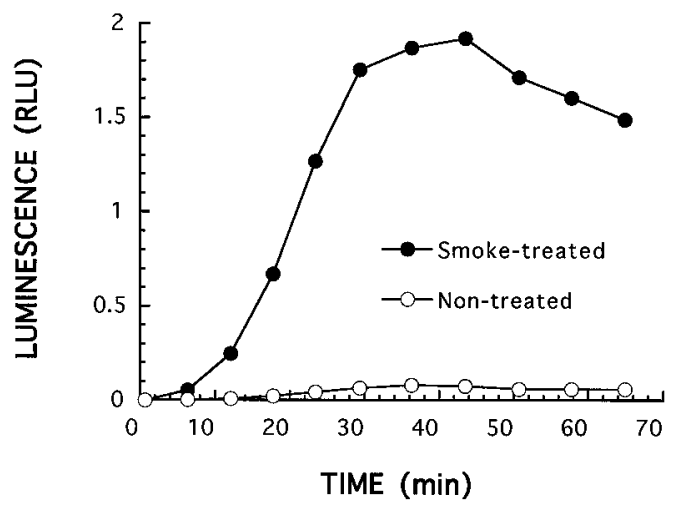

FIG. 8. Cigarette smoke induces DPD2511 luminescence. The experimental conditions used are described in Materials and Methods. Time zero was the end of direct exposure to smoke and the beginning of luminescence monitoring.

cellular events involved. (ii) They may be used as very convenient tools for assaying the oxidant and antioxidant properties of chemicals, food additives, etc. (iii) They may be used as sensitive tools for monitoring and assessing the hazards in environmental samples in different media, including drinking water, wastewater, soil, and air; this can be accomplished by using isolated batch samples or may be part of an on-line early warning system.

\section{ACKNOWLEDGMENTS}

This work was carried out during a sabbatical leave of S. Belkin with the DuPont Company, the support of which is gratefully acknowledged.

G. Storz is thanked for generously providing E. coli strains.

\section{REFERENCES}

1. Altuvia, S., M. Almiron, G. Huisman, R. Kolter, and G. Storz. 1994. The dps promoter is activated by OxyR during growth and by IHF and sigma $\mathrm{S}$ in stationary phase. Mol. Microbiol. 13:265-272.

2. Belkin, S., T. K. Van Dyk, A. C. Vollmer, D. R. Smulski, and R. A. LaRossa. Monitoring sub-toxic environmental hazards by stress-responsive luminous bacteria. Environ. Toxicol. Water Qual., in press.

3. Belkin, S., A. C. Vollmer, T. K. Van Dyk, D. R. Smulski, T. R. Reed, and R. A. LaRossa. 1994. Oxidative and DNA damaging agents induce luminescence in E. coli harboring lux fusions to stress promoters, p. 509-512. In A. K. Campbell, L. J. Kricka, and P. E. Stanley (ed.), Bioluminescence and chemiluminescence: fundamentals and applied aspects. John Wiley and Sons, Chichester, England.

3a.Belkin, S., et al. Unpublished data
4. Bouffard, G., J. Ostell, and K. E. Rudd. 1992. GeneScape: a relational data base of Escherichia coli genomic map data for Macintosh computers. CABIOS 8:563-567.

5. Crawford, D. R., C. A. Edbauer-Nechamen, C. V. Lowry, S. L. Salmon, Y. K. Kim, J. M. S. Davies, and K. J. A. Davies. 1994. Assessing gene expression during oxidative stress. Methods Enzymol. 234:175-217.

6. Davies, K. J. A., and S. W. Lin. 1988. Degradation of oxidatively denatured proteins in Escherichia coli. Free Radic. Biol. Med. 5:215-223.

7. Demple, B. 1991. Regulation of bacterial oxidative stress genes. Annu. Rev. Genet. 25:315-337.

8. Greenberg, J. T., J. H. Chou, P. A. Monach, and B. Demple. 1991. Activation of oxidative stress genes by mutations at the soxQ/cfxB/marA locus of Escherichia coli. J. Bacteriol. 173:4433-4439.

9. Halliwell, B., and J. M. C. Gutteridge. 1989. Free radicals in biology and medicine, 2nd ed. Clarendon Press, Oxford.

10. Kohara, Y., K. Akiyama, and K. Isono. 1987. The physical map of the whole E. coli chromosome: application of a new strategy for rapid analysis and sorting of a large genomic library. Cell 50:495-508.

11. Meighen, E. M., and P. V. Dunlap. 1993. Physiological, biochemical and genetic control of bacterial bioluminescence. Adv. Microb. Physiol. 34:1-67.

12. Menzel, R. 1989. A microtiter plate-based system for the semiautomated growth and assay of bacterial cells for $\beta$-galactosidase activity. Anal. Biochem. 181:40-50.

13. Miller, J. H. 1972. Experiments in molecular genetics. Cold Spring Harbor Laboratory Press, Cold Spring Harbor, N.Y.

14. Rogowsky, P. M., T. J. Close, J. A. Chimera, J. J. Shaw, and C. I. Kado. 1987. Regulation of the vir genes of Agrobacterium tumefaciens plasmid pTiC58. J. Bacteriol. 169:5101-5112.

15. Sambrook, J., E. F. Fritsch, and T. Maniatis. 1989. Molecular cloning: a laboratory manual, 2nd ed. Cold Spring Harbor Laboratory Press, Cold Spring Harbor, N.Y.

16. Stewart, G. S. A. B., and P. Williams. 1992. lux genes and the applications of bacterial bioluminescence. J. Gen. Microbiol. 138:1289-1300.

17. Storz, G., and S. Altuvia. 1994. OxyR regulon. Methods Enzymol. 234:217223

18. Storz, G., L. A. Tartaglia, S. B. Farr, and B. N. Ames. 1990. Bacterial defenses against oxidative stress. Trends Genet. 6:363-368.

19. Triggs-Raine, B. L., B. W. Doble, M. R. Mulvey, P. A. Sorby, and P. C Loewen. 1988. Nucleotide sequence of kat G, encoding catalase HPI of Escherichia coli. J. Bacteriol. 170:4415-4419.

20. Van Dyk, T. K., S. Belkin, A. C. Vollmer, D. R. Smulski, T. R. Reed, and R. A LaRossa. 1994. Fusions of Vibrio fischeri lux genes to Escherichia coli stress promoters: detection of environmental stress, p. 147-150. In A. K. Campbell, L. J. Kricka, and P. E. Stanley (ed.), Bioluminescence and chemiluminescence: fundamentals and applied aspects. John Wiley and Sons, Chichester, England.

21. Van Dyk, T. K., W. R. Majarian, K. B. Konstantinov, R. M. Young, P. S. Dhurjati, and R. A. LaRossa. 1994. Rapid and sensitive pollutant detection by induction of heat shock gene-bioluminescence gene fusions. Appl. Environ. Microbiol. 60:1414-1420.

22. Van Dyk, T. K., T. R. Reed, A. C. Vollmer, and R. A. LaRossa. 1995 Synergistic induction of the heat shock response in Escherichia coli by simultaneous treatment with chemical inducers. J. Bacteriol. 177:6001-6004.

23. Van Dyk, T. K., D. R. Smulski, T. R. Reed, S. Belkin, A. C. Vollmer, and R. A. LaRossa. 1995. Responses to toxicants of an Escherichia coli strain carrying a $u \operatorname{sp} A^{\prime}:: l u x$ genetic fusion and an $E$. coli strain carrying a grp $E^{\prime}:: l u x$ fusion are similar. Appl. Environ. Microbiol. 61:4124-4127.

24. Vollmer, A. C., et al. Unpublished data. 